\section{A CASE OF POISONING FROM VERONAL}

\section{JOHN GERMANN, M.D.}

\section{BROOKLYN, N. Y.}

Patient.-E. G., aged 22, male, a school teacher, unmarried, was found in a state of profound coma from which he could not be roused and died 79 hours afterward.

History.-The attending physician makes the following statement: "E. G., a young man of intelligence and a patient of over two years' standing, came to my office on the afternoon of January 13 and stated that he was suffering from insomnia. I advised against the use of any drug, telling him that the drug habit was worse than the rum habit. I advised him to give up a night class he was teaching and to try a hot bath at bedtime. He said that he could not give up the class and that he got home too late to take a bath. After some further talk I was about to write for a simple sedative when he asked me if I would not write for veronal, as his sister was taking it with marked benefit. I said that I had not used the drug, but that Merck's preparations were standard. The statement in the newspapers that I asked him how to spell the name of the drug is untrue. He obtained on my prescription a vial containing fifty $5 \mathrm{gr}$. tablets, with directions to take two tablets at bedtime. There were no directions to repeat or to increase the dose. So far as is known; he took none at bedtime. According to his father's testimony he went to his room at $9: 30$ Sunday morning and at 12:30 was found sleeping so soundly that he could not be roused. The vial was empty and none of the drug was found." The patient is supposed to have become impatient and to have taken from 200 to 250 grains instead of waiting for one or two doses to take effect.

Symptoms.-When found, four hours after a hearty breakfast, the pulse was 90 , respiration 24 . Half an hour before death, 79 hours later, pulse was 152 , respiration 44 , temperature 108.5. During the last 24 hours the respiration was irregular and stertorous and the man was cyanosed. The heart seemed the least affected; the pulse was of good quality till the last four hours.

Treatment.-Cathartic enemas were given and also high rectal enemas of hot saline solution. Coffee, caffein, diureties, strychnin, oxygen, adnephrin, and saline solution by hypodermoclysis were all tried but without effect. After 24 hours, the urine contained albumin and a specimen 2 hours before death contained 33 per cent.

Autopsy.-The brain and all the organs were found deeply congested (but only slight edema at brain). The organs, especially the abdominal, were dark and the blood was chocolate colored. The stomach, especially, was greatly congested, with a hole 3 inches in diameter-caused by postmortem digestion.

Coroner's Verdict.—“E. G. came to his death on the 17th day of January, 1906, at 90 Norman Avenue, by cerebral congestion and edema, and nephritis caused by taking an overdose of veronal to produce sleep."

Remarks.-If any symptoms could be of an unusual char. acter, I should judge they were the following: 1 . Persistence of the coma for a period of 79 hours. 2. The fact that the pulse remained of a good character over such a period of time. 3 . The gradual and steady rise of temperature from normal to 108.4 antemortem. 4. The increase of the respirations from 24 to 44 . $u$. The fact that cyanosis should appear so late in the case. 6. The presence of albuminous urine. 7. The intense cerebral congestion, found postmortem, and the very slight edema. 8. The discoloration of the organs-deep congestion, and the altered blood-dark chocolate color. 9. The intense congestion of the stomach, especially of the cardiac end, and the postmortem digestion of the large space of three and one-half inches in diameter.

Concerning the manner of prescribing veronal, I can make no comments. The physician ordered 1 bottle of $5 \mathrm{gr}$. tablets of veronal (Merck). Dose 2 at bedtime. The dispensing druggist, not having a full bottle of 100 on hand, gave the young man 50 tablets. The only remedy, in my opinion, is to wash the stomach thoroughly if the case is seen within 2 or 3 hours after the ingestion of the drug.

\section{A NEW EXTENSION SPLIN'T.}

\section{J. P. HETHERINGTON, M.D.}

Surgeon for Pennsylvania, Vandalia, and Wabash Rallroad and Union Traction Co.

LOGANSPORT, IND.

I am never called to treat a fracture of the hip or femur without feeling that I wish it could have been some other bone. Many methods of treatment have been tried, almost any one of which means that the patient must remain on his back for from four to six weeks. The pneumatic splint allows a patient to leave his bed, but the yielding air cushions do not give a stable point of extension and the splint is heavy. In bed the roll under the thigh and the rods down the back of the legs lack comfort.

Several years ago I studied the various methods of obtaining the upper bearing. Some surgeons used the perineum and others the axilla for the various extensions and crutch splints. I talked with the makers of artificial legs, and nearly all advised a hard, firm substance, slightly padded, for an artificial leg socket, so I decided that if a solid support were required to sustain the weight of the body it would certainly be sensible to have the same kind of support for a sustained extension of from five to twenty-five pounds on a broken leg. I tried the upper part of an artificial leg socket instead of the perineal band. Then I had half a dozen variously shaped hip and perineal bands hammered out of aluminum, until I finally succeeded in getting quite a comfortable hip. piece. This threw nearly all the weight on the ischium, almost entirely relieving the perineal pressure. The hammered aluminum, however, was brittle and would crack, so I had a light steel band made to fit the hip, and around this placed a shaped mold of fiber and leather. This made a splint that was easy, comfortable, and borne well day after day, but being constructed of steel and leather, it was heavy, and when permeated by various discharges its peculiar odor put it out of use.

I have made several unsuccessful attempts to have the splint cast of pure aluminum, but one maker after another gave it up until recently, when an expert patiently worked at it until he made a set of three sizes, both right and left. The medium size will fit nearly any ordinary person.

I had him make a "skeleton framework" consisting only of adjustable inside and outside rods and footpiece so that $I$ could apply splints between or bandage around them (Fig. 1). Being lightly constructed of pure aluminum it is not strong enough to bear a heavy weight while walking on crutches, but a splint weighs less than four pounds complete. It will not rust, and being of solid metal it can be scrubbed or boiled. I have found it painful to use a bandage or pneumatic pad above the ankle for extension fastening, so I use the adhesive plaster along each side of the leg. The upper part, which I call a "hip housing," fits tightly. The broad thin metal is far more steady and comfortable than a narrow ring, and adds to the comfort in bed. While the pneumatic ring forms a thick pad and undesirably forces the upper fragment upward, the thin housing occupies almost no space between the hip and bed, assists in holding a short upper fragment inward, and, if padded underneath, helps to elevate the sacrum in guarding against bed sores. At the same time it is clear off the median line and aids rather than hinders evacuation of the bowels.

This seems to be another step toward making these patients more comfortable while obtaining the desired extension. 